\title{
The impact of changing wildfire regimes on wood availability from Portuguese forests
}

\author{
Francisco Rego $^{\mathrm{a}, *}$, Graça Louro ${ }^{\mathrm{b}}$, Luís Constantino ${ }^{\mathrm{c}}$ \\ a Instituto Superior de Agronomia, Centro de Ecologia Aplicada Baeta Neves (CEABN/INBIO), Tapada da Ajuda, 1349-017 Lisboa, Portugal

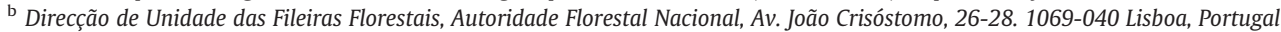 \\ c Forest Economics, World Bank, 1818 H Street, NW, Washington, DC 20433, United States
}

\section{A R T I C L E I N F O}

Available online 29 January 2013

\section{Keywords:}

Wood availability

Timber production

Wildfire

Forest inventory

Maritime pine

Eucalyptus

\begin{abstract}
A B S T R A C T
The perception of the good capability of the Portuguese mainland for timber production has sustained forest expansion policies during the twentieth century. These policies led to an increase of production forests, maritime pine (Pinus pinaster) first and eucalyptus (Eucalyptus globulus) later to support establishment and development of wood based industries (sawn, pulp and paper). The most recent forest inventory from 2005/6 estimated an area of 885,000 ha for maritime pine ( $8.9 \%$ of the country) and 740,000 ha for eucalyptus (7.5\%). Today wood based industries (sawn, pulp and paper) are important for jobs and economy, using essentially the raw material produced in the country.

However, forests are at high risks of wildfires, with pine and eucalyptus burning at an annual rate of 3-4\% between 1996 and 2005. This resulted in great concerns about the sustainability of the national supply of wood to forest industries. As a consequence the National Forest Strategy (DGRF, 2007) recognized the decrease of risks associated with wildfires as a main policy objective.

We predict the effect of different wildfire scenarios on wood availability for pine and eucalyptus forests with Markov chain models, by using national forest inventory and wildfire data.
\end{abstract}

(C) 2012 Elsevier B.V. All rights reserved.

\section{Introduction}

The prediction of future trends of wood availability based on current forest inventories is essential to sustain policy and economic decisions of public and private agents of the forest sector. These predictions require a modelling approach. This issue has been an important topic in the research done in recent years for the forest sector of various countries as Russia (Solberg et al., 2010) and Norway (Trømborg and Solberg, 2010), different regions as Europe (Toppinen and Kuuluvainen, 2010) and even at the global scale (Buongiorno et al., 2003; Raunikar et al., 2010). One of the possible approaches for the modelling of the forest sector and the prediction of wood availability is based on the use of Markov chains (Päivinen, 1996).

However, these models generally do not incorporate risk. On the other side, most of the published work on integrating risk in forestry (Arbez et al., 2002; Olabarria, 2006) do not predict timber volume trends or use Markov chains. One of the few examples of the use of Markov chains for risk analysis in the context of timber harvest planning is presented by Yashimoto (2001). We followed the same approach to evaluate the implications of wildfires on wood availability for Portugal by using data from forest inventories and wildfires.

\footnotetext{
This article belongs to the Special Issue: Fire use policies and practices in Europe: Solving the Fire Paradox.

* Corresponding author. Tel.: + 351213616085 ; fax: + 351213623493.

E-mail address: fcastrorego3@gmail.com (F. Rego).
}

In Portugal it is clear that the increase of capacity of wood based industries is strongly related with the increase of timber availability (Louro et al., 2009, 2010a). As a consequence, domestic consumption of wood by industries is closely related to timber production (Fig. 1).

Although the availability of wood within Portugal is an important advantage of the forest sector compared to other important economic activities that are based on imported raw materials, the sustainability of timber supply to the industries is associated with risks and uncertainty. This is a result of different factors, caused by natural, social and economic transformations, at the international and the national levels (DGRF, 2007).

Included in the changes of context is climate change which is known to increase wildfire risk (Santos et al., 2002), and these changes have obvious effects on wood availability. As a consequence, the forecasting of timber availability related to wildfire regimes and harvesting levels is becoming more important in the decision making process, especially in the planning of forest strategies and future investments.

In this paper, we use a simple model allowing for the understanding and forecasting of wood availability for maritime pine and eucalyptus as a result of different wildfire and harvesting regimes.

\section{Methodology}

\subsection{Data sources}

Time series data of forest areas and volumes, by age classes, are published by the Portuguese Forest Service, under the framework of 


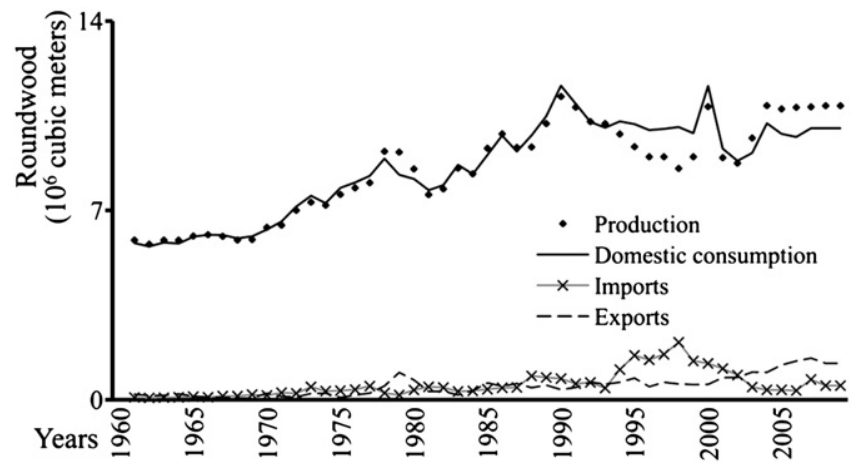

Fig. 1. Evolution of production, domestic consumption, imports and exports of roundwood (mainly maritime pine and eucalyptus) in Portugal.

Source: FAOSTAT system, URL: http://faostat.fao.org/site/626/default.aspx\#ancor.

the National Forest Inventories (NFI) and in other related publications from 1971 to 2010 . These data have been compiled, described and analyzed by Louro et al. (2010b).

In the case of the two main wood production species, maritime pine (Pinus pinaster) and eucalyptus (Eucalyptus globulus), the distribution of areas by age classes are reported for the following years:

(i) maritime pine - 1971, 1982, 1992, 1995 and 2005.

(ii) eucalyptus - 1971, 1984, 1992, 1995 and 2005.

The data published by these inventories include both regular (even aged) and irregular (uneven aged) stands. For regular stands the following age classes were considered:

(i) maritime pine - 6 age classes of 10 -year intervals up to 60 years, and one age class of more than 60 years.

(ii) eucalyptus -3 age classes of 4 -year intervals up to 12 years, and one age class of more than 12 years.

The information about annual burnt areas from 1996 to 2005 by forest type was taken from the National Forest Strategy (DGRF, 2007), indicating annual percentages of burnt areas of $4.0 \%$ and of $3.4 \%$, respectively, for maritime pine and eucalyptus.

\subsection{Simplifications}

In order to develop the model, we made some simplifications:

(i) Only maritime pine and eucalyptus were considered because they are the main species supplying timber for industrial transformation (AFN, 2010).

(ii) Only pure stands (both regular and irregular) were considered as mixed stands of maritime pine and eucalyptus are less important (Fig. 2).

\subsection{Exploratory analysis}

We sought to explore the possible relationships between the areas of stands in the various age classes, in successive inventories.

For eucalyptus, this analysis is difficult to perform since there is a discrepancy between the age class intervals ( 4 years) and the period between inventories (10 years).

For maritime pine inventories are made at 10-year intervals, so it was possible to establish a relationship between successive age classes. The linear relationship obtained indicated a slope of 0.73 , as an estimate of the general probability for a stand to transit in 10 years for the next age class without wildfires, harvesting or annual conversions. This simple relationship indicated that it should be possible to explore further the relationships between successive age class distributions of maritime pine by using more detailed approaches including regimes of wildfire and forest management.

\subsection{Modelling approach: Markov chains}

The methodology followed for modelling and for the prediction of wood availability was based on the use of Markov chains (Päivinen, 1996, Yashimoto, 2001).

This method requires the $n \times 1$ vector $X_{t}$, with the classification of forests areas, at time $t$, in $n$ different age classes, where $x_{i}^{t}$ represents the area of the age class $i(i=1,2, \ldots . n)$ at that time.

The use of Markov chains requires also the introduction of the $n \times n$ probability square transition matrix $P_{i, j}^{t}$, at time $t$, where each $P_{i, j}^{t}$, is the probability for the stand at the age class $i$, in time $t$, to be at age class $i+1$, in time $t+1$.

The product of the two matrices gives the distribution of the occupation areas, by age class, in time $t+1$ (Yashimoto, 2001), as follows:

$$
\begin{aligned}
X_{t+1}^{\prime} & =X_{t}^{\prime} \cdot P_{t}=\left(x_{1}^{t+1} x_{2}^{t+1} \ldots x_{n}^{t+1}\right) \\
& =\left(x_{1}^{t} x_{2}^{t} \ldots x_{n}^{t}\right) \cdot\left[\begin{array}{ccccc}
p_{1,1}^{t} & p_{1,2}^{t} & p_{1,3}^{t} & \cdot & p_{1, n}^{t} \\
p_{2,1}^{t} & p_{2,2}^{t} & p_{2,3}^{t} & \cdot & p_{2, n}^{t} \\
p_{3,1}^{t} & p_{3,2}^{t} & p_{3,3}^{t} & \cdot & p_{3, n}^{t} \\
\cdot & \cdot & \cdot & \cdot & \cdot \\
p_{n, 1}^{t} & p_{n, 2}^{t} & p_{n, 3}^{t} & \cdot & p_{n, n}^{t}
\end{array}\right]
\end{aligned}
$$

where ' represents transpose.

This theoretical model was used to establish the current probability transition matrices for maritime pine and eucalyptus termed as the base scenario matrices.

For the base scenario (Bs) the parameters to be estimated for the transition matrices are the annual probability of a forest to stay in the same age class $(\alpha)$ or to transition to the next age class $(\beta=1-\alpha)$ due to the aging process, the annual probability of harvesting $(h)$, wildfire $(w)$, or conversion from regular to irregular stands $(c)$.
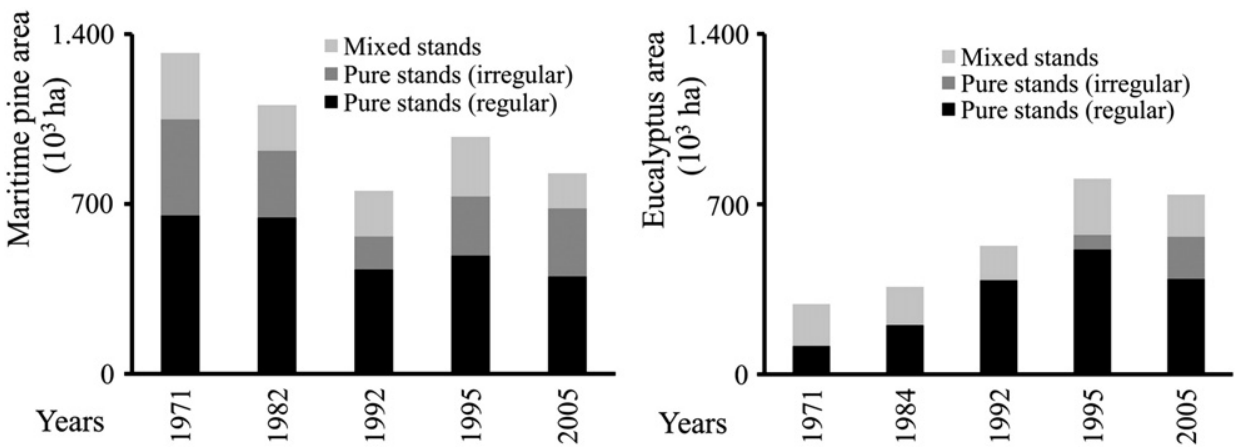

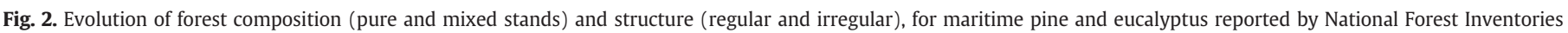
(NFI), between 1971 and 2005. 
Table 1

Volumes of wood per hectare for maritime pine by age classes published in National Forest Inventory NFI 2005/6.

\begin{tabular}{lc}
\hline Maritime pine & NFI 2005/6 \\
\cline { 2 - 2 } Age class (years) & Timber volume $\left(\mathrm{m}^{3} / \mathrm{ha}\right)$ \\
\hline$<10$ & 8.7 \\
$10-20$ & 61.8 \\
$20-30$ & 118.1 \\
$30-40$ & 167.7 \\
$40-50$ & 210.0 \\
$50-60$ & 227.5 \\
$>60$ & 269.4 \\
Irregular & 88.5 \\
\hline
\end{tabular}

Table 2

Volumes of wood per hectare for eucalyptus by age classes published in the National Forest Inventory NFI 2005/6.

\begin{tabular}{lc}
\hline Eucalyptus & NFI 2005/6 \\
\cline { 2 - 2 } Age class (years) & Timber volume $\left(\mathrm{m}^{3} / \mathrm{ha}\right)$ \\
\hline$<4$ & 5.1 \\
$4-8$ & 29.5 \\
$8-12$ & 83.9 \\
$>12$ & 101.3 \\
irregular & 62.2 \\
\hline
\end{tabular}

For maritime pine, the value for the annual probability of a stand to remain in the same 10 -year-age class is $\alpha=0.9$ and the probability to transit to the next 10-year-age class is $\beta=1-\alpha=0.1$. For eucalyptus, with 4-year-age classes, the probability to remain in the same class is $\alpha=0.75$ and the probability to transit to the next age class is $\beta=1-\alpha=0.25$.

We assumed that eucalyptus stands younger than 4 years of age do not burn and that harvesting in eucalyptus does not occur before age 12 years. It was also assumed that conversions to irregular stands only occur from the older regular stands (more than 50 years in maritime pine and more than 12 years in eucalyptus).

A National Forest Strategy Scenario (NFSs) was also established. This scenario is different from the base scenario in the annual probability of wildfires $(w)$ that was set equal to 0.008 , for both maritime pine and eucalyptus, as this is the national policy target assumed by the Strategy for the annual proportion of burnt area (DGRF, 2007).

\subsection{Parameter estimation for the base scenario}

In order to provide a common base for the simulations a base scenario (Bs) was established. For this base scenario it was assumed that, in the future, the probabilities of change in the areas of irregular and regular stands (by age class) were similar to those observed in the period between the two last forest inventories NFI 1995/6 and NFI 2005/6.

The calibration of the base scenario was done with the estimation of three annual probabilities: wildfires $(w)$; harvesting of wood $(h)$; conversion to irregular stands $(c)$. This was done by minimizing the sum of the squares between the observed values of the distribution of areas by age class in NFI 2005/6 (o) and the corresponding estimated values $(e)$ using the Markov chains: $\min \Sigma(o-e)^{2}$.

\subsection{Calculation of standing volumes}

The calculation of the standing volumes $V_{t}$ associated with the estimated areas obtained by the use of Markov chains was done by the application of the equation

$V_{t}=\sum_{i=1}^{n} v_{i} x_{i}^{t} p_{i, j}^{t}$

where the volume per hectare for the age class $i\left(v_{i}\right)$ was considered to be constant in the time of study $(t, t+1, \ldots, t+n)$, and equal to the data published in the inventory of 2005/6 (AFN, 2010) for maritime pine (Table 1 ) and eucalyptus (Table 2 ).

\section{Results and discussion}

\subsection{Distribution of age classes in regular stands}

For maritime pine, the distribution of areas by age class (Fig. 3), shows a shift from a unimodal distribution, with modes in the middle age classes (20 to 40 years), in the first three forest inventories (1971, 1982, 1992), to a more uniform distribution in 1995.

After 1995 another change occurred to a unimodal distribution with the mode in the first age class $(<10$ years), reflecting the dramatic impact of the severe wildfire regimes.

For eucalyptus, the distribution of the areas by age class (Fig. 3), is different from that observed for maritime pine. The continuous increase in the total area of eucalyptus, observed in Fig. 2, is consistent

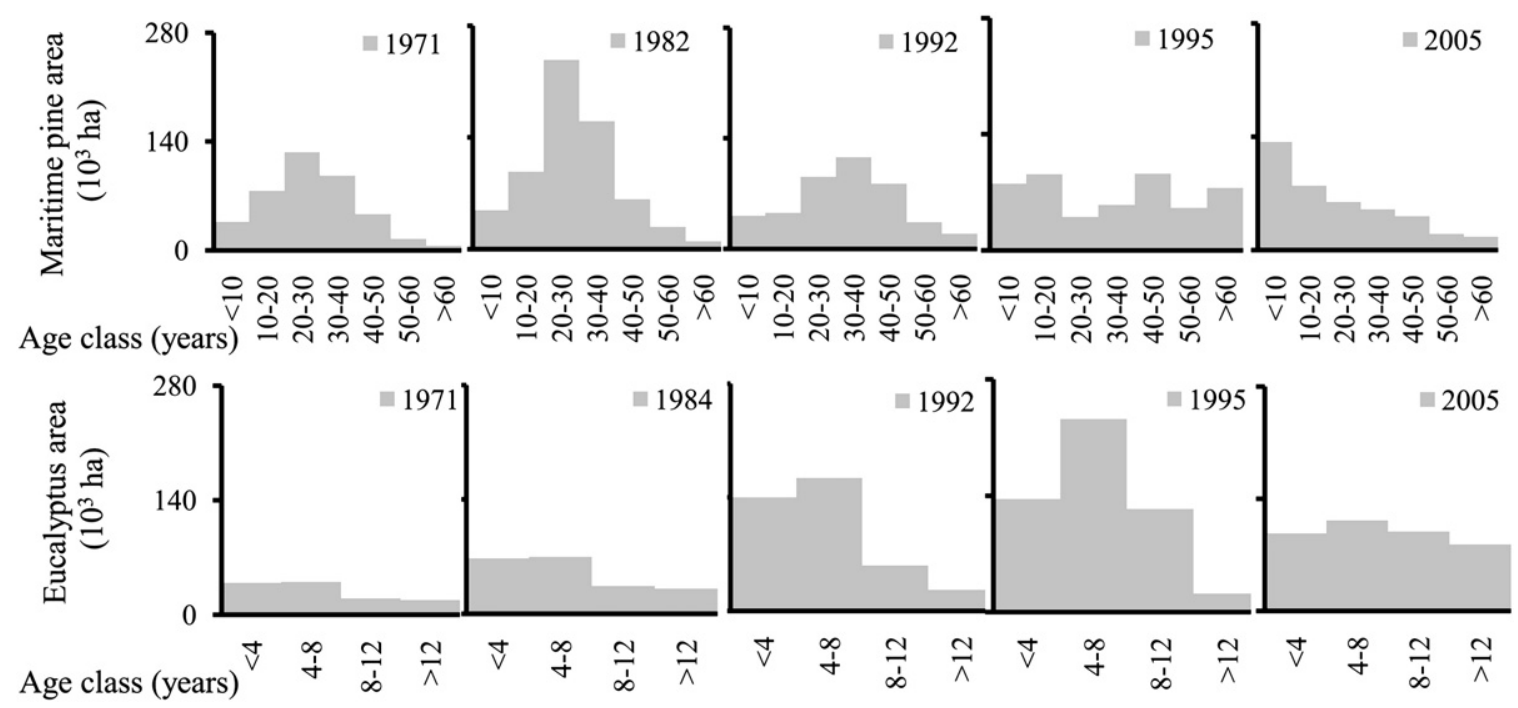

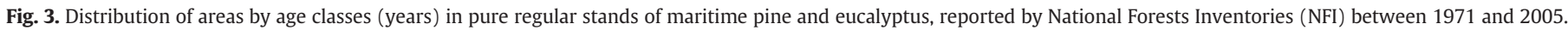




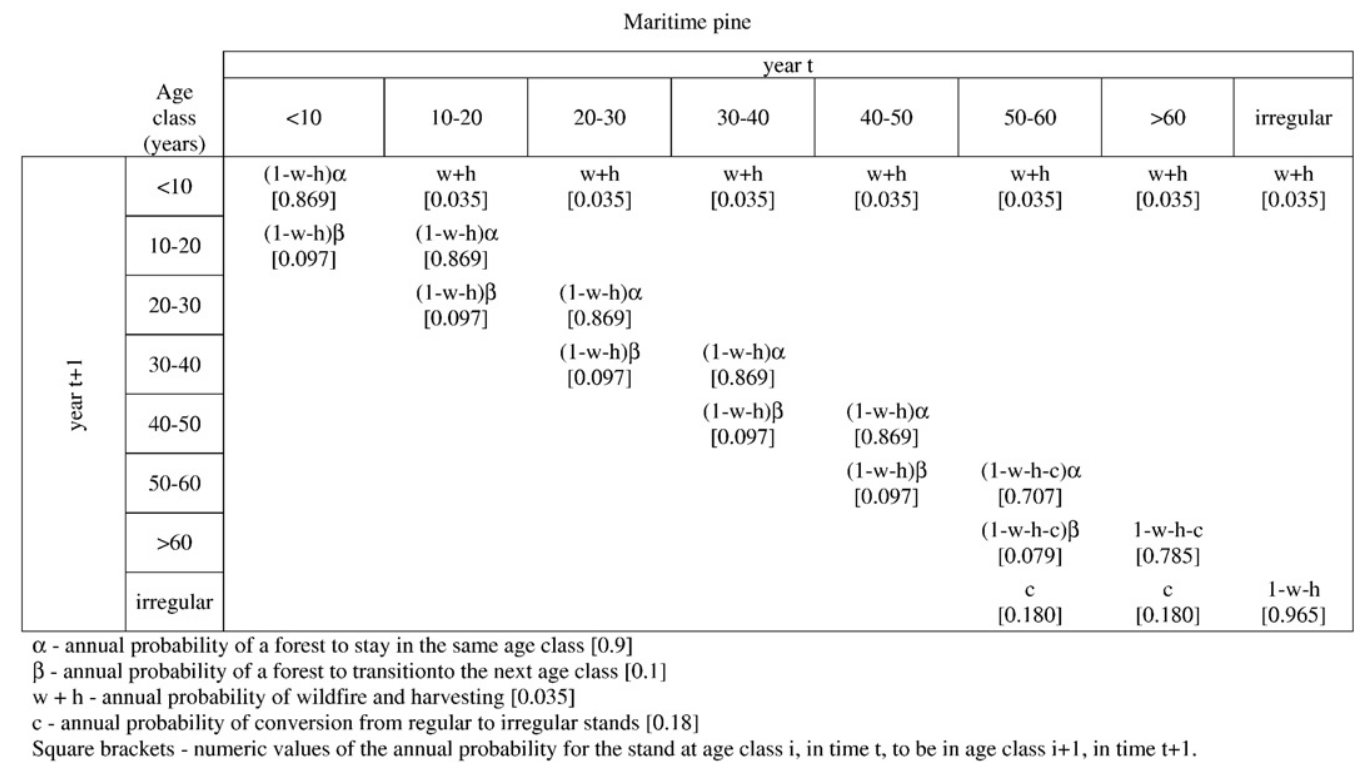

Fig. 4. Probability transition matrix for maritime pine.

with the dominance of younger stands in the first inventories (1971, 1984, 1992 and 1995).

This pattern changed in the last forest inventory (2005), showing a more uniform distribution for the different age classes. This change in pattern is possibly related with decisions that postpone the harvesting of older eucalyptus stands.

\subsection{Estimated values for the transition matrices}

The estimated annual probability values obtained for the base scenario (Bs) in the calibration process for the parameters $w, h$ and $c$ are indicated in Fig. 4, for maritime pine, and in Fig. 5, for eucalyptus.

For maritime pine the estimated probability combining wildfire and harvesting $(w+h=0.035)$ for all age classes, is close to the observed value of 0.040 for the annual proportion of burnt areas between 1996 and 2005 (DGRF, 2007), suggesting that the decision to harvest is often taken as a result of a wildfire event, as it is generally perceived but poorly documented.

For eucalyptus the estimated probability for wildfires $(w=0.047)$ is higher than the observed annual proportion of burnt areas (0.034), but the values are quite comparable as the parameter for wildfires only applies for stands above 4 years of age.

The estimated value for wildfire and harvesting for eucalyptus regular stands above 12 years and irregular stands $(w+h=0.067)$ is much higher than the observed burnt proportion of 0.034 (DGRF, 2007). This indicates that, contrary to what was observed for maritime pine, a good proportion of decisions to harvest are not related to the occurrence of wildfires.

Eucalyptus

\begin{tabular}{|c|c|c|c|c|c|c|}
\hline & \multirow[b]{2}{*}{$\begin{array}{l}\text { Age class } \\
\text { (years) }\end{array}$} & \multicolumn{5}{|c|}{ year t } \\
\hline & & $<4$ & $4-8$ & $8-12$ & $>12$ & irregular \\
\hline \multirow{5}{*}{$\begin{array}{l}\underset{ \pm}{ \pm} \\
\underset{\varpi}{ \pm}\end{array}$} & $<4$ & \multirow{5}{*}{$\begin{array}{c}\alpha \\
{[0.750]} \\
\beta \\
{[0.250]}\end{array}$} & $\begin{array}{c}w \\
{[0.047]}\end{array}$ & \multirow[t]{2}{*}{$\begin{array}{c}\mathrm{w} \\
{[0.047]}\end{array}$} & \multirow[t]{3}{*}{$\begin{array}{c}\mathrm{w}+\mathrm{h} \\
{[0.067]}\end{array}$} & \multirow[t]{4}{*}{$\begin{array}{c}\mathrm{w}+\mathrm{h} \\
{[0.067]}\end{array}$} \\
\hline & $4-8$ & & $\begin{array}{l}(1-w) \alpha \\
{[0.715]}\end{array}$ & & & \\
\hline & $8-12$ & & $\begin{array}{l}(1-w) \beta \\
{[0.238]}\end{array}$ & $\begin{array}{l}(1-w) \alpha \\
{[0.715]}\end{array}$ & & \\
\hline & $>12$ & & & $\begin{array}{l}(1-w) \beta \\
{[0.238]}\end{array}$ & $\begin{array}{l}1-w-h-c \\
{[0.661]}\end{array}$ & \\
\hline & irregular & & & & $\begin{array}{c}c \\
{[0.272]}\end{array}$ & $\begin{array}{c}1-w-h \\
{[0.933]}\end{array}$ \\
\hline \multicolumn{7}{|c|}{$\begin{array}{l}\alpha-\text { annual probability of a forest to stay in the same age class }[0.75] \\
\beta \text { - annual probability of a forest to transition to the next age class }[0.25] \\
\text { w- annual probability of wildfire }[0.047] \\
h \text { - annual probability of harvesting [0.020] } \\
\text { c - annual probability of conversion from regular to irregular stands }[0.272] \\
\text { Square brackets - numeric values of the annual probability for the stand at age class } i \text {, in time } \\
\text { t, to be in age class } i+1, . \text { in time } t+1 .\end{array}$} \\
\hline
\end{tabular}

Fig. 5. Probability transition matrix for eucalyptus. 

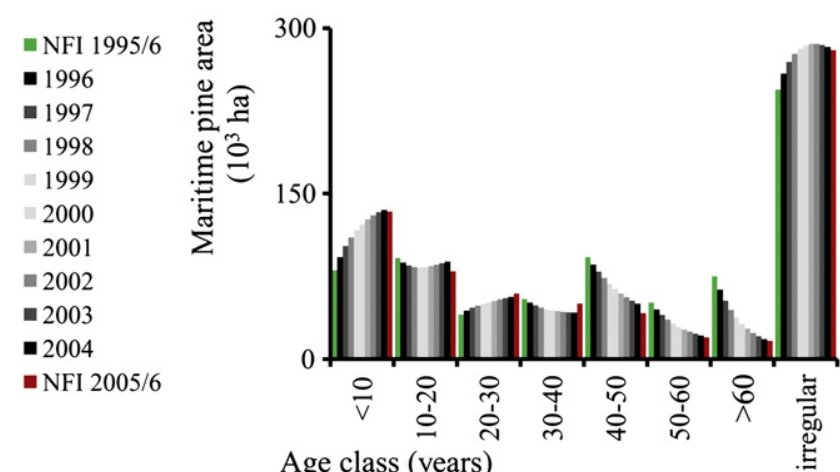

Age class (years)

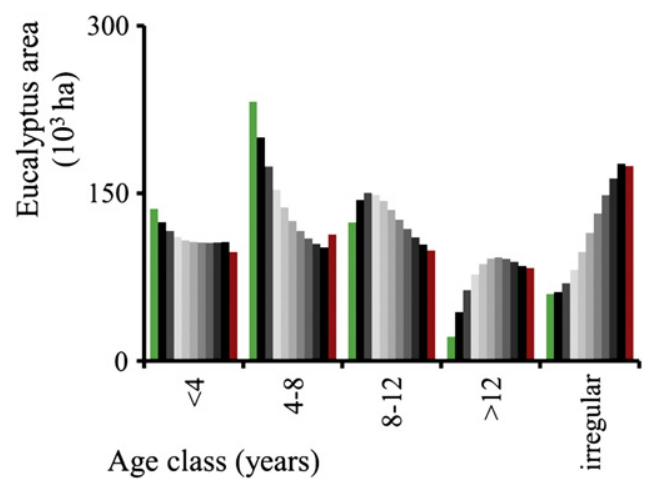

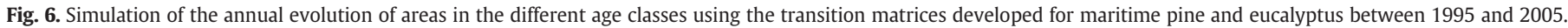

\subsection{Simulation of areas by age classes}

The two annual transition probability matrices produced for maritime pine and eucalyptus (Figs. 4 and 5), were used to explain the possible behavior of the evolution of the areas between the forest inventories of 1995/6 and 2005/6.

For both maritime pine and eucalyptus this simulation was based on the product of the initial vectors for $1995 / 6$, by the corresponding annual transition matrices. The estimations were made annually for all classes from 1996 until 2004 and are shown in comparison with the published data of NFI 2005/6 (Fig. 6).

\subsection{Forecasting of trends in volumes until 2015}

For maritime pine, the volumes obtained in the simulation for the base scenario (Fig. 7) show a trend for a decrease of wood in regular

a)

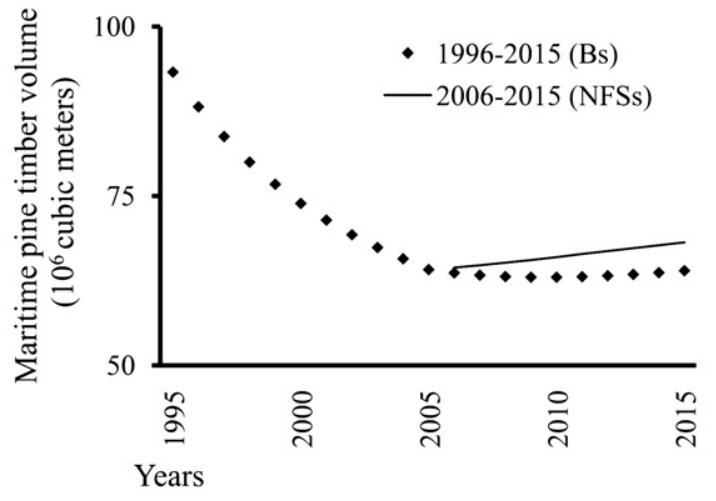

a)

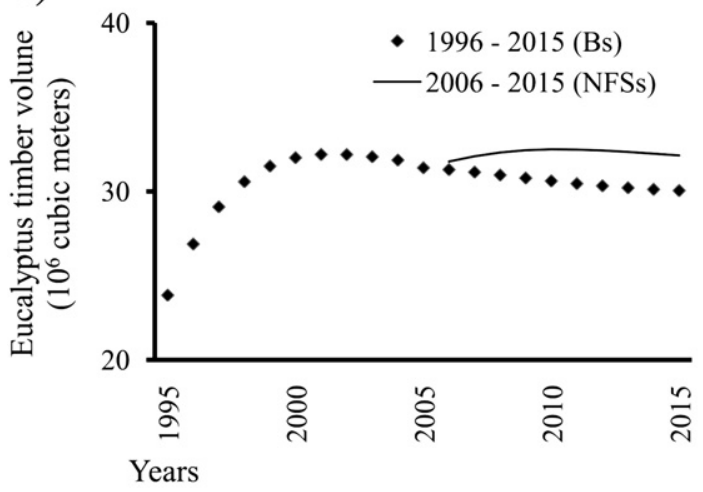

stands from 39.3 to 35.1 million $\mathrm{m}^{3}$ especially in older stands (more than 30 years). This decrease is compensated by a similar increase in irregular stands from 24.8 to 28.9 million $\mathrm{m}^{3}$. If these trends are confirmed the risks associated with the supply of round wood to sawn industries will continue, as it has been already indicated in previous studies (Bento, 1994).

For eucalyptus, the base scenario also predicts a general reduction of the standing volumes in all the regular stands from 20.5 to 16.0 million $\mathrm{m}^{3}$, and an increase of volumes on the irregular stands from 10.8 to 14.0 million $\mathrm{m}^{3}$ resulting in a reduction of total volume from 31.4 to 30.0 million $\mathrm{m}^{3}$ until 2015 (Fig. 7). This trend may be changed with more active management practices which prevent changes from regular to irregular stands.

On both species the reduction of wildfire regime to the annual proportion of 0.008 aimed by the National Forest Strategy scenario (DGRF, 2007) will have a positive consequence on the availability of wood for

b)

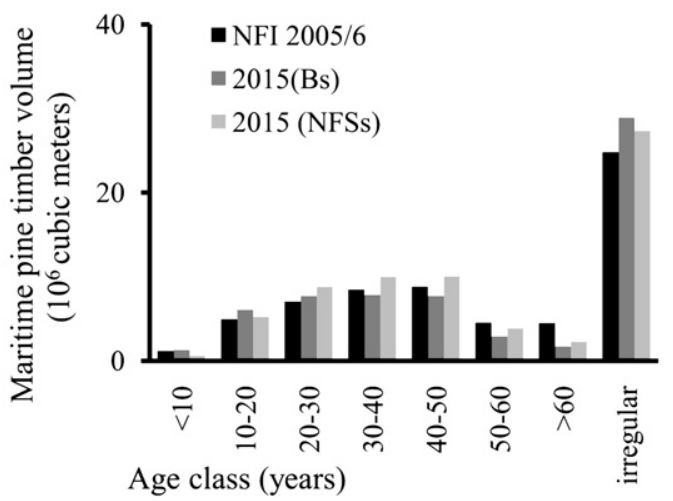

b)

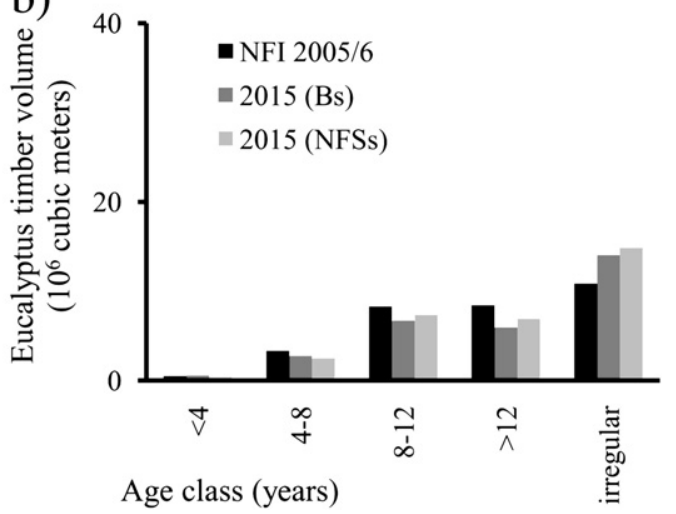

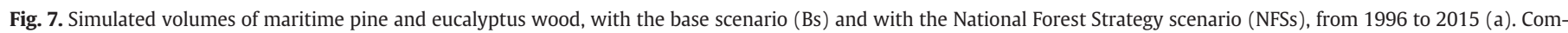
parison of NFI 2005/6 published volumes with the volumes simulated for 2015 with the two scenarios (b). 
industry, particularly in the case of maritime pine where the total wood volume available would increase from 64.1 to 68.1 million $\mathrm{m}^{3}$ until 2015. For eucalyptus with this scenario the total volume available in 2015 would increase to 32.1 million $\mathrm{m}^{3}$ instead of the negative trend of the base scenario.

\section{Final synthesis}

The use of Markov chains seems to be a simple and effective methodology to predict wood availability in Portugal, confirming that "....simple models concentrating on a limited issue could be easily build, used and discarded, and might provide sufficient rigor of analysis with a further advantage of being highly transparent in use" (Toppinen and Kuuluvainen, 2010).

In fact, the model is simple as it uses a limited number of parameters, which can be easily interpreted with related statistics. The model is also effective in representing the major factors affecting wood availability in Portugal. The model is limited by the assumptions taken in its development and it can be further improved as more detailed data becomes available. Assuming these limitations the model is a good tool in the understanding of the national forest sector system and in providing general guidance in forest policy strategies.

The results of the study show that the maintaining of the base scenario will have as consequence:

(i) a decrease on the availability of round wood for sawn from regular stands, especially in older stands;

(ii) a transition of eucalyptus from regular to irregular stands, less interesting for the industrial transformation to produce wood pulp.

The accomplishment of the targets established by the National Forest Strategy by reducing the annual burnt area to less than 0.008 will contribute to a gradual recovery of wood availability for maritime pine and eucalyptus. Reducing the wildfire risk is confirmed to be a first order priority for the Portuguese forests.

The continued conversion of regular to irregular stands is probably explained by the tendency for a less active forest management. The encouragement of sustainable forest management practices must therefore be a priority for the Portuguese forest sector.

The simultaneous achievement of both objectives, reducing wildfire risk and promote sustainable forest management, in a situation of highly fragmented properties, can be obtained by the encouragement of common forest management units with an adequate size (DGRF, 2007).

These paper express the authors opinion and not of the organizations where they work.

\section{References}

AFN, 2010. 5ํ Inventário Florestal Nacional 2005-2006 Relatório final. Autoridade Florestal Nacional, Lisboa.

Arbez, M., Birot, Y., Carnus, J.M. (Eds.), 2002. Risk Management and Sustainable Forestry, Joeensu, EFI Proceedings No. 85. European Forest Institute.

Bento, J., 1994. Oferta Sustentada de Material Lenhoso de Pinheiro Bravo, uma aplicação nacional. Universidade de Trás-os-Montes e Alto Douro, Vila Real.

Buongiorno, J., Zhu, S., Zhang, T., Turner, J., Tomberlin, D., 2003. The Global Forest Products Model. Elsevier Science, USA.

DGRF, 2007. National Forest Strategy. Direcção-Geral dos Recursos Florestais, Lisbon.

Louro, G., Constantino, L., Gravato, L., Rego, F., 2009. A Fileira da Construção e do Mobiliário: Análise de Contexto. Silva Lusitana, vol. 17(I). Instituto Nacional de Investigação Agrária, Lisboa, pp. 59-82.

Louro, G., Constantino, L., Leal, L., Gravato, A., Rego, F., Louro, G., Constantino, L., Leal, L., Gravato, A., Rego, F., 2010a. A Fileira do Papel e do Cartão e a Fileira das Embalagens: Análise de Contexto. Silva Lusitana, 18(I). Instituto Nacional de Investigação Agrária, Lisboa, pp. 1-26.

Louro, G., Monteiro, M., Constantino, L., Tomé, M., Rego, F., 2010b. Evolução do material lenhoso de pinheiro bravo e eucalipto. Silva Lusitana, vol. 18(2). Instituto Nacional de Investigação Agrária, Lisboa, pp. 133-149.

Olabarria, J. 2006, Integrating fire risk into forest planning, Helsinki, The Finish Society of Forest Science, Dissertationes Forestales 23.

Päivinen, R., 1996. Large-scale forestry scenario models - where we are? In: Päivinen, Risto, Roihuvuuo, Leena, Siitonen, Markku (Eds.), EFI Proceedings No. 5. European Forest Institute (EFI), Joensuu, Finland, pp. 5-14.

Raunikar, R. Buongiorno, J., Turner. J., Zhu, S., 2010. Global outlook for wood and forests with the bioenergy demand implied by scenarios of the Intergovernmental Panel on Climate Change. Forest Policy and Economics, 12. Elsevier, pp. 48-56.

Santos, F.D., Forbes, K., Moita, R. (Eds.), 2002. Climate Change in Portugal. Scenarios, Impacts and Adaptation Measures - SIAM Project, Gradiva, Lisbon.

Solberg, B., Moiseyev, A., Kallio, A., Toppinen, A., 2010. Forest sector market impacts of changed roundwood export tariffs and investment climate in Russia. Forest Policy and Economics, 12. Elsevier, pp. 17-23.

Toppinen, A., Kuuluvainen, J., 2010. Forest sector modeling in Europe - the state of the art and future research directions. Forest Policy and Economics, 12. Elsevier, pp. 2-8.

Trømborg, E., Solberg, B., 2010. Forest sector impacts of the increased use of wood in energy production in Norway. Forest Policy and Economics, 12. Elsevier, pp. 19-47.

Yashimoto, A., 2001. Risk analysis in the context of timber harvest planning. In: Van Gadow, Klaus (Ed.), Risk Analysis in Forests Management. Kluwer Academic Publishers, Germany, pp. 113-148. 